\title{
A Conceptual Aerospace Vehicle Structural System Modeling, Analysis and Design Process
}

\author{
Vivek Mukhopadhyay ${ }^{1}$ \\ NASA Langley Research Center, Hampton, Virginia, 23681-2199
}

A process for aerospace structural concept analysis and design is presented, with examples of a blended-wing-body fuselage, a multi-bubble fuselage concept, a notional crew exploration vehicle, and a high altitude long endurance aircraft. Aerospace vehicle structures must withstand all anticipated mission loads, yet must be designed to have optimal structural weight with the required safety margins. For a viable systems study of advanced concepts, these conflicting requirements must be imposed and analyzed early in the conceptual design cycle, preferably with a high degree of fidelity. In this design process, integrated multidisciplinary analysis tools are used in a collaborative engineering environment. First, parametric solid and surface models including the internal structural layout are developed for detailed finite element analyses. Multiple design scenarios are generated for analyzing several structural configurations and material alternatives. The structural stress, deflection, strain, and margins of safety distributions are visualized and the design is improved. Over several design cycles, the refined vehicle parts and assembly models are generated. The accumulated design data is used for the structural mass comparison and concept ranking. The present application focus on the blended-wing-body vehicle structure and advanced composite material are also discussed.

$\begin{array}{ll}A R & =\text { Aspect ratio } \\ \mathrm{b} & =\text { Wing span } \\ \mathrm{c} & =\text { Reference chord length } \\ E x, E y & =\text { Young's Modulus } \\ g & =\text { Gravitational acceleration constant } \\ \text { Gxy } & =\text { Shear Modulus } \\ \text { psi } & =\text { Pounds per square inch } \\ \text { Abbreviations } & \\ \text { BWB } & =\text { Blended Wing Body } \\ \text { CAD } & =\text { Computer Aided Design } \\ \text { CM } & =\text { Command Module } \\ \text { CEV } & =\text { Crew Exploration Vehicle } \\ \text { FEM } & =\text { Finite Element Model } \\ \text { HALE } & =\text { High Altitude Long Endurance Vehicle } \\ \text { IDC } & =\text { Integrated Design Center } \\ \text { IGES } & =\text { Initial Graphic Exchange Specification } \\ \text { MTGW } & =\text { Maximum Takeoff Gross Weight } \\ \text { SFW } & =\text { Subsonic Fixed Wing } \\ \text { SRFI } & =\text { Stitched Resin Film Infusion }\end{array}$

\section{Introduction}

$\mathrm{D}$ URING the conceptual design of an aerospace vehicle, the structural analysis and mass estimation require significant experience and extrapolation of available data from previously developed vehicles ${ }^{1-5}$, conceptual design tools $^{6-7}$, and statistical methods ${ }^{8-9}$. This task is particularly difficult for an unconventional vehicle concept development, with extreme missions and flight load requirements ${ }^{10-13}$. A large number of structural design options and material alternatives need to be considered in order to select the most viable configuration, with optimal structural weight. In this paper, a physics based interactive multidisciplinary approach is described for the analysis

\footnotetext{
${ }^{1}$ Senior Aerospace Engineer, Aeronautical Systems Analysis Branch, ms 442: AIAA Associate Fellow. It is a NASA Policy not to endorse any commercial product used in this study.
} 
and design of novel structural configurations. In this design process, high fidelity parametric solid and surface models of the vehicle and its components are developed for detailed finite element analysis. The primary design parameters and model dimensions are based on the initial conceptual design ${ }^{2,6,7}$. The vehicle outer mold line is then defined using these key design parameters, such as the outer diameter, vehicle length, wing plan-form, wing area, aspect ratio, airfoil shape etc. This is followed by the internal structural layout and finite element analysis. The structural members are initially sized using finite element analysis of each model with the estimated design loads, including the internal pressure and aerodynamic loads. In extreme cases where the aerodynamic load estimation is not adequate, the aerodynamic pressure is computed and the loads are transferred to the finite element model for further analysis. This detailed internal structural layout and the design oriented finite element analysis tools are particularly desirable in the conceptual design cycle, in order to reduce the risk of structural weight growth in future.

A variable fidelity structural, aerodynamic and control analysis process under the Conceptual Design Shop (CDS) project was described in Ref. 14. The project objective was to assemble and seamlessly integrate a complete set of software for the structural, aerodynamics, controls, propulsion, noise, and aeroelastic analysis. Figure 1 shows a schematic diagram of these software toolsets for multi-disciplinary analysis and optimization. The CDS project teams developed an aircraft conceptual design process by integrating existing flight optimization tools ${ }^{7}$ and integration methods ${ }^{15}$. This software integration tool also included a web-based collaboration and distributed computing capability. The 'Control' team provided the capability to analyze the stability and control characteristics of a subsonic vehicle using MATLAB ${ }^{16}$ based codes. The 'Geometry, Structural Layout and Packaging' team integrated tools for the development of parametric geometry, outer mold line, internal structural layout and finite element analysis. An interactive aircraft design tool AMRAVEN $^{17}$ was customized using an Adaptive Modeling Language ${ }^{17}$. This tool also generated input files for the meshing and finite element analysis in NASTRAN/PATRAN ${ }^{18}$. The structural layout files were also converted to the IGES (Initial Graphic Exchange Specification) files, and the geometry was

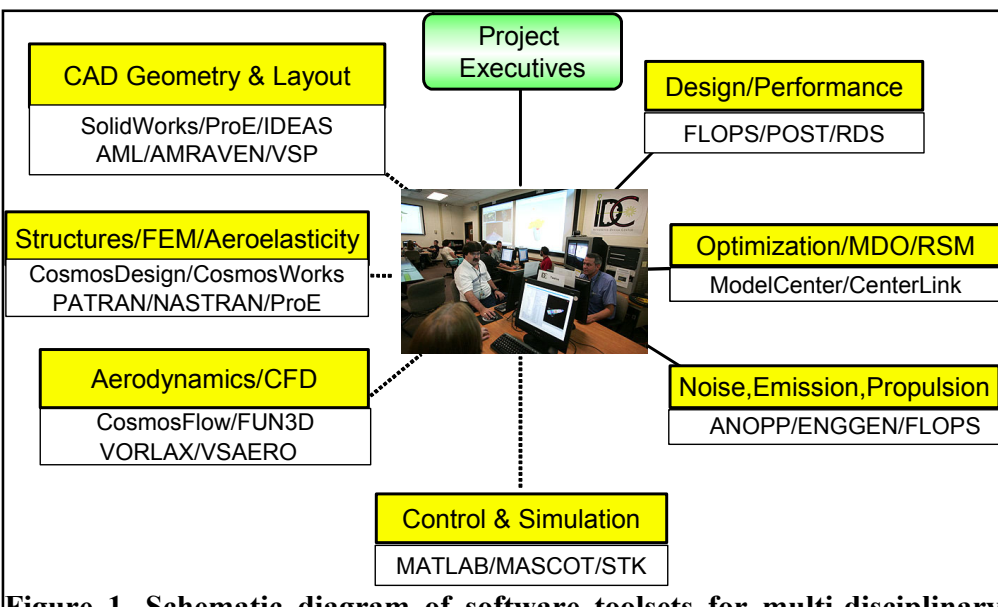

Figure 1. Schematic diagram of software toolsets for multi-disciplinary analysis and optimization.

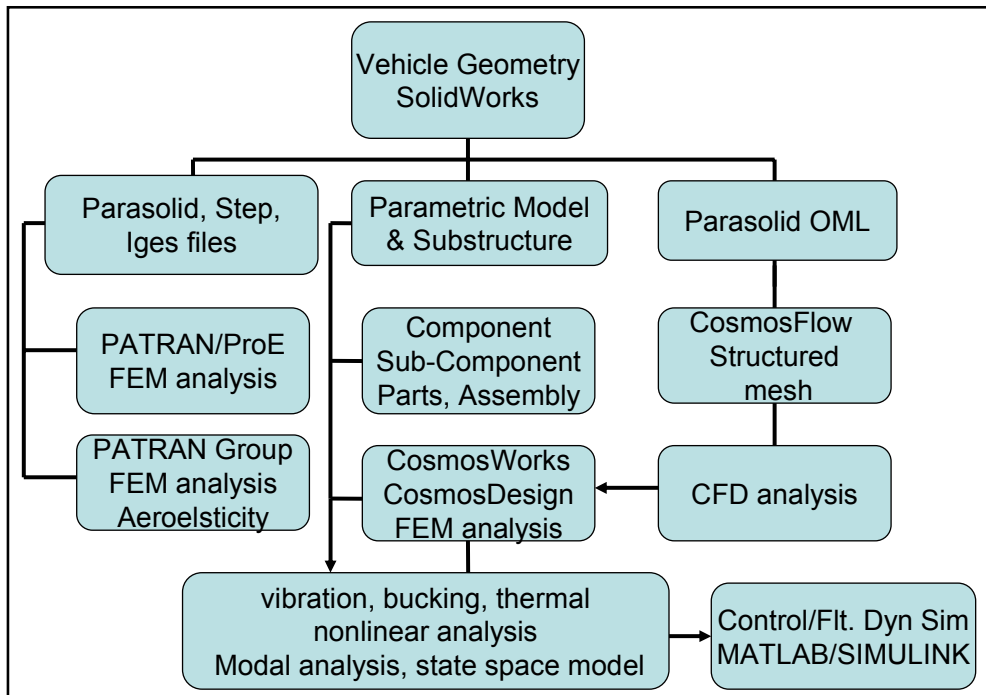

Figure 2. Functionality and interaction of CAD based software toolsets for parametric model generation, structural analysis and design. regenerated in SolidWorks ${ }^{19}$. The subsequent structural design was conducted with CosmosDesign ${ }^{20}$.

The efficiency and flexibility of the structural design process was significantly improved by developing the vehicle models directly in SolidWorks ${ }^{19}$ in the ParaSolid format, which is a widely used 3-dimensional geometry modeling kernel. The design oriented finite element model (FEM) analysis, and the computational fluid dynamics (CFD) analysis are performed with the integrated application software CosmosWorks ${ }^{20}$. Figure 2 shows the functionality and interface of these CAD based software toolsets for the parametric model generation, structural analysis and design. The vehicle configuration development, internal structural layout, assembly, FEM analysis, CFD analysis, sizing and optimization, are all performed on a network of computers at the Integrated Design Center 
(IDC) in the Systems Engineering Directorate at NASA Langley. The IDC computer cluster also includes a variety of other analysis and simulation tools for aerospace applications.

A major objective of this work is the enhancement of systems analysis capabilities under the recently established Fundamental Aeronautics Program at NASA ${ }^{21}$. This integrated process is presently being used for the Blended Wing Body (BWB) vehicle structural design under the Subsonic Fixed Wing (SFW) project in the areas of advanced composite materials and structures. This paper is organized as follows. The basic steps for the parametric model development, structural finite element analysis and design are outlined in section II. Then illustrative examples of: i) a BWB mega transport fuselage design, ii) an alternate multi-bubble fuselage concept, iii) a notional crew exploration vehicle analysis, and iv) a high altitude long endurance vehicle wing design, are presented in the next four sections. Summary of the analysis and design results for concept ranking are presented in the appendix. From the lessons learned, the design process will be improved.

\section{Model Development, Structural Analysis and Design Process}

Basic steps for the parametric model development, structural finite element analysis and design improvement are outlined below.

1. Generate baseline vehicle: Determine initial dimensions and geometry layout. Establish the key geometric parameters of the vehicle and components. Determine parametric relations of all other dimensions with the key geometric parameters (e.g., span, root-chord, taper ratio, etc.).

2. Develop parametric solid and surface models: Generate the vehicle outer mold line, structural components, and internal layout. The structural components may include wing, fuselage, center-box, empennage, crew capsule, inter-stage ring, high pressure tanks, etc. Add parametric relations to the internal layout (e.g., rib spacing, frame spacing, number of ribs and frames, etc.).

3. Assemble the structural components: Resolve packaging and volume interference problems between the vehicle and its internal components. This may include redesign of internal components. Develop initial weight statement as a guideline from conceptual design report or empirical procedure.

4. Define structural design loads: Identify the most critical design loading conditions. Compute aerodynamic loading distribution analytically or numerically, using the CFD solution utility, if necessary.

5. Generate finite element analysis data: Compute the stress, deflection and safety margins for initial sizing under these loading conditions. Use solid model for coupon level analysis. Use surface models for sub-component and vehicle level analysis. Locate problem areas for redesign.

6. Conduct design study: Change key design parameter values, and improve the design. Check stress, deflection

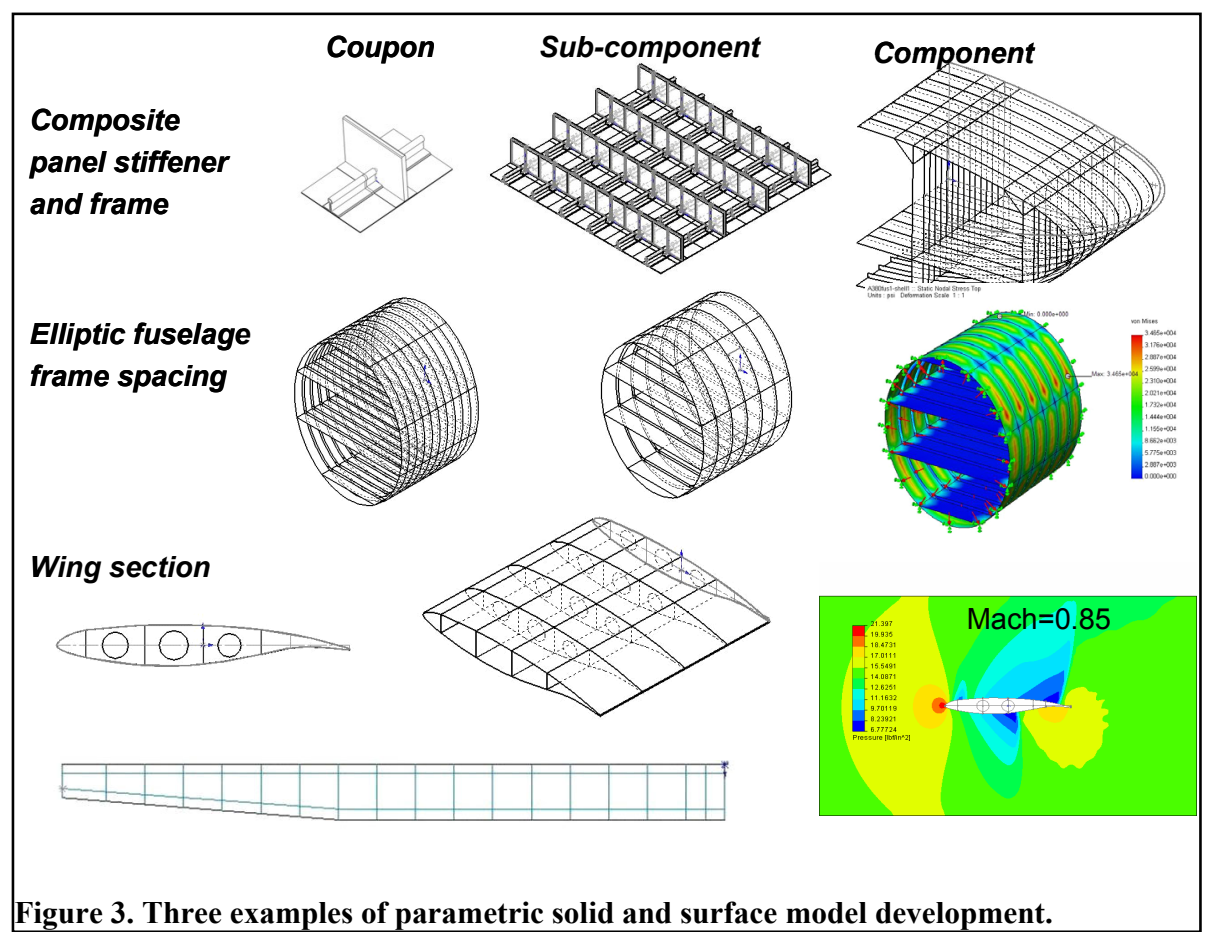

Figure 3. Three examples of parametric solid and surface model development. and safety margins. Generate the design database, and weight statement. Rank concepts based on critical design considerations.

Figure 3 illustrates three examples of parametric solid and surface model development. In these examples, key geometric parameters are used to generate coupon, subcomponent, component level models of a composite stiffened panel, an elliptic fuselage and a wing section. The composite panel stiffener and frame in the coupon level are usually solid models. This facilitates accurate layout and proper application of 
the anisotropic material properties of the sandwich core and face sheets. The coupon level models are assembled to create sub-component models for the next level of analysis. In the assembly process, the frame and stiffener spacing are also used as key design variables. Thus, several design options can be quickly modeled and analyzed in order to improve the design. The component level models are usually surface models for rapid meshing and analysis using shell elements. The second row in Fig. 3 shows the development of an elliptic cross section fuselage. In this case the cross section and frame geometry are created first. Then, a single ring section part is created. Multiple instances of this part are assembled and connected to form a fuselage section. The ring section can be easily modified to create another fuselage section with different frame spacing. A sample stress analysis results with a 9.3 psi internal pressure loads are shown at right. The last row of Fig. 3 shows the development of a super-critical wing-section model. In this example, the number of spars and ribs may be used as design variables. A constant chord wing was modeled by repeating a segment of the 3D surface model. The $2 \mathrm{D}$ pressure distributions on the airfoil were computed using CosmosFlow ${ }^{20}$, as shown in the lower right contour plot. When the wing plan-form is tapered, the wing outer mold line is created first at each end of the tapered segment. Then the surface is split at rib-spacing intervals. For a fully defined wing, the key design parameters can be changed or scaled to form a class of wing models. A library of vehicle components can be created for modification and assembly. The BWB fuselage design example is presented next.

\section{BWB Mega Transport}

A non-cylindrical pressurized fuselage of the BWB vehicle generally has a higher structural weight fraction, compared to a cylindrical fuselage. For the weight estimation of a conventional transport class aircraft, design handbooks ${ }^{4,6}$ or a suitable flight systems optimization software ${ }^{7}$ may be used. Figure 4 shows the weight breakdown results of a transport class vehicle, by using the statistical empirical formulae from Raymer ${ }^{6}$. The computations and graphic plots are programmed in Matlab $^{16}$. The bar charts show the weight breakdown of a B747 class of aircraft with a maximum takeoff gross weight (MTGW) of 713,000 lbs. The last bar chart shows the weight fraction of the four major weight groups, i.e., structure, propulsion, payload, and fuel. The structural weight fraction of a conventional transport aircraft is generally $25 \%$ of the MTGW. These formulae were applied for the mass estimation of a BWB mega transport concept ${ }^{12}$ with a MTGW of $804,813 \mathrm{lbs}$. The weight breakdown results are shown in Fig. 5. In this case, the horizontal tail formula was used for the aft body, and the vertical tail formula was used for the two wing tip rudders. The fuselage formula was applied to an ellipsoid. The structural weight fraction of this BWB vehicle was estimated at over $33 \%$ of the MTGW. Although this empirical extrapolation to the BWB vehicle was highly speculative, the increased weight fraction trend was right. For such an unconventional vehicle, a detailed FEM had to be developed and analyzed, for a better evaluation of the

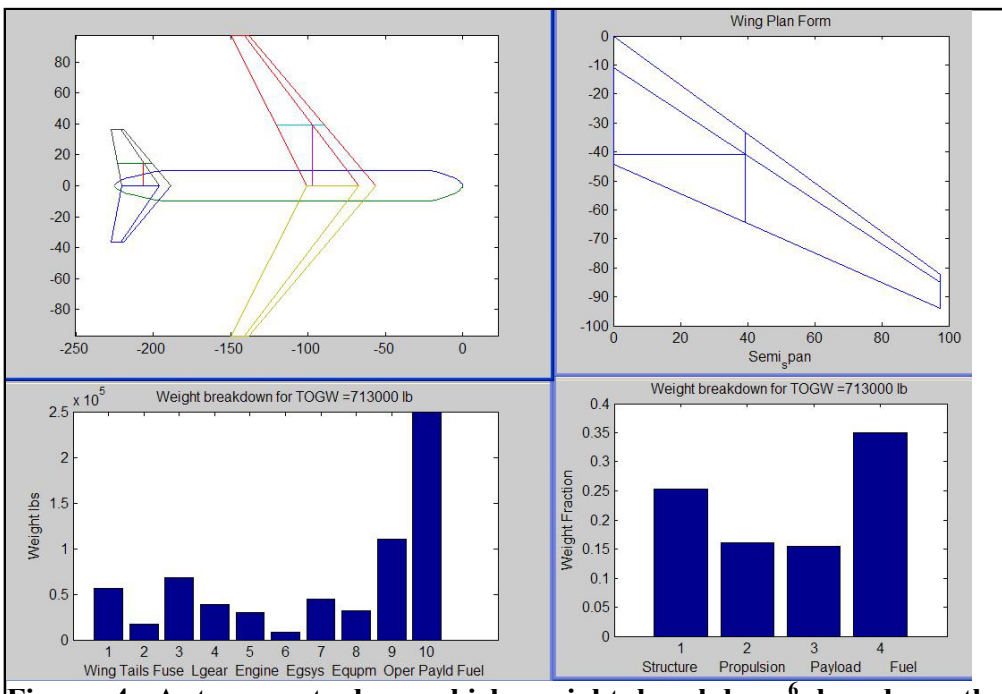

Figure 4. A transport class vehicle weight breakdown ${ }^{6}$ based on the maximum take-off gross weight.

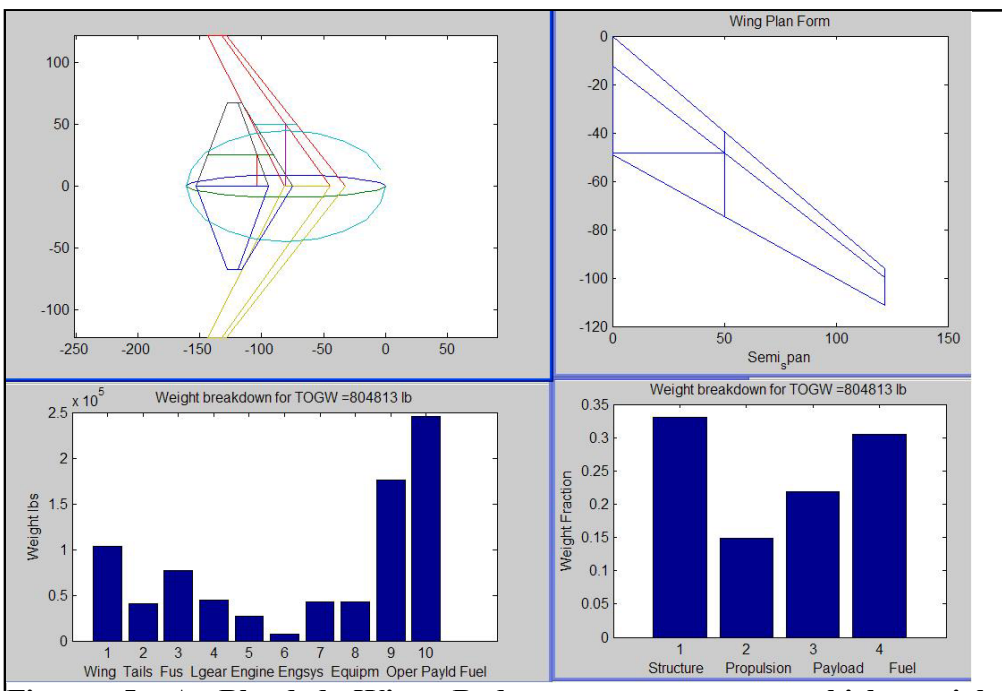

Figure 5. A Blended Wing Body mega transport vehicle weight breakdown ${ }^{6}$ based on the maximum take-off gross weight. 
structural concept and component weight. This type of structural systems analysis was conducted for the first generation of the $\mathrm{BWB}^{21}$ concept in order to down-select the most efficient structural configuration. Results of this investigation were reported in Ref. 22 and a summary is shown in Fig. 6.

Baseline vehicle: The baseline vehicle and loading conditions were obtained from the BWB conceptual design documents ${ }^{12}$. The internal structural configuration of Bay 3 of the fuselage was studied, since it is at a critical location where the fuselage blends into the wing. FEM models of four structural configurations, namely, 1) a double skin vaulted ribbed shell, 2) a double skin flat ribbed shell, 3) a vaulted shell with a light honeycomb core, and 4) a flat shell with a light honeycomb core, were developed and studied.

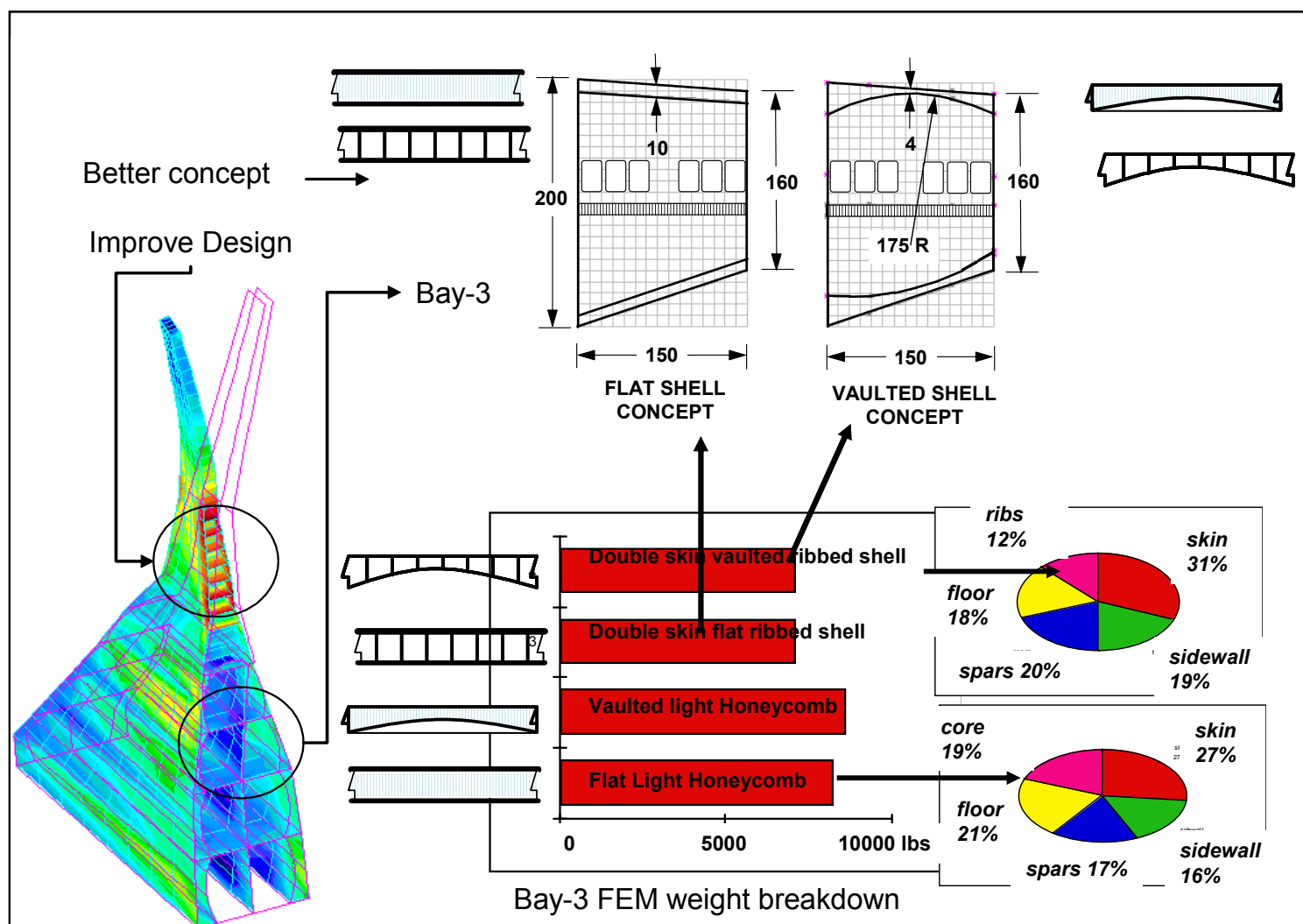

Figure 6. The Blended wing Body (BWB) mega transport structural concept analysis and FEM weight comparison.

Key Design Parameters: The shell element thicknesses for the inner and outer skin, ribs, spars and sandwich face-sheets were chosen as key design parameters.

Structural Design Loads: The flight condition at $2.5 \mathrm{~g}$ pull up at maximum takeoff gross weight (MTGW) was considered to be critical for the limit load computation. A typical bending moment, shear force and torque distribution based on elliptic span-wise loading on a swept cantilever beam were determined for this critical load case. The limit loads at the fuselage section were estimated to be: bending moment $27 \times 10^{6} \mathrm{ft}-\mathrm{lbs}$, shear load $25 \times 10^{4}$ $\mathrm{lbs}$, and torque $13.4 \times 10^{6} \mathrm{ft}-\mathrm{lbs}$, at the inboard side of the Bay-3 fuselage section. These loads were multiplied by a safety factor of 1.5 to obtain the ultimate design loads. For finite element analysis purposes, bending moments were converted to equivalent tension and compression forces at the upper- and lower-surface skin element nodes. The equivalent compressive running load on upper surface was estimated at $4000 \mathrm{lbs} / \mathrm{inch}$. The shear and torque loadings were converted to equivalent forces at the appropriate element nodes. The ultimate design pressure load was assumed to be $18.6 \mathrm{psi}$. The mid-deck floor loading was assumed to be $0.625 \mathrm{psi}$. The aerodynamic pressure loads on the fuselage section were neglected compared to the 18.6 psi ultimate cabin pressure.

Finite element analysis: The initial sizing of the skin and core thickness was done using simple beam-column analysis. Four FEM models of the Bay-3 were developed and analyzed using the critical flight load condition at $2.5 \mathrm{~g}$ pull-up. Advanced composite material properties were used for the face sheet of the deep sandwich with aluminum honeycomb core. Figure 6 shows the weight comparison of these four concepts. The percentage weight contributions of the structural components are also presented as pie charts. 
Weight Analysis and concept ranking: From the manufacturing and structural weight considerations, the doubleskin flat-ribbed (span-wise and chord-wise) shell was preferable, although the corresponding vaulted concept FEM weight was nearly equal. Advanced composite material was preferable compared to the aluminum construction.

In the present BWB baseline vehicle structure, a similar flat-ribbed (span-wise and chord-wise) SRFI shell

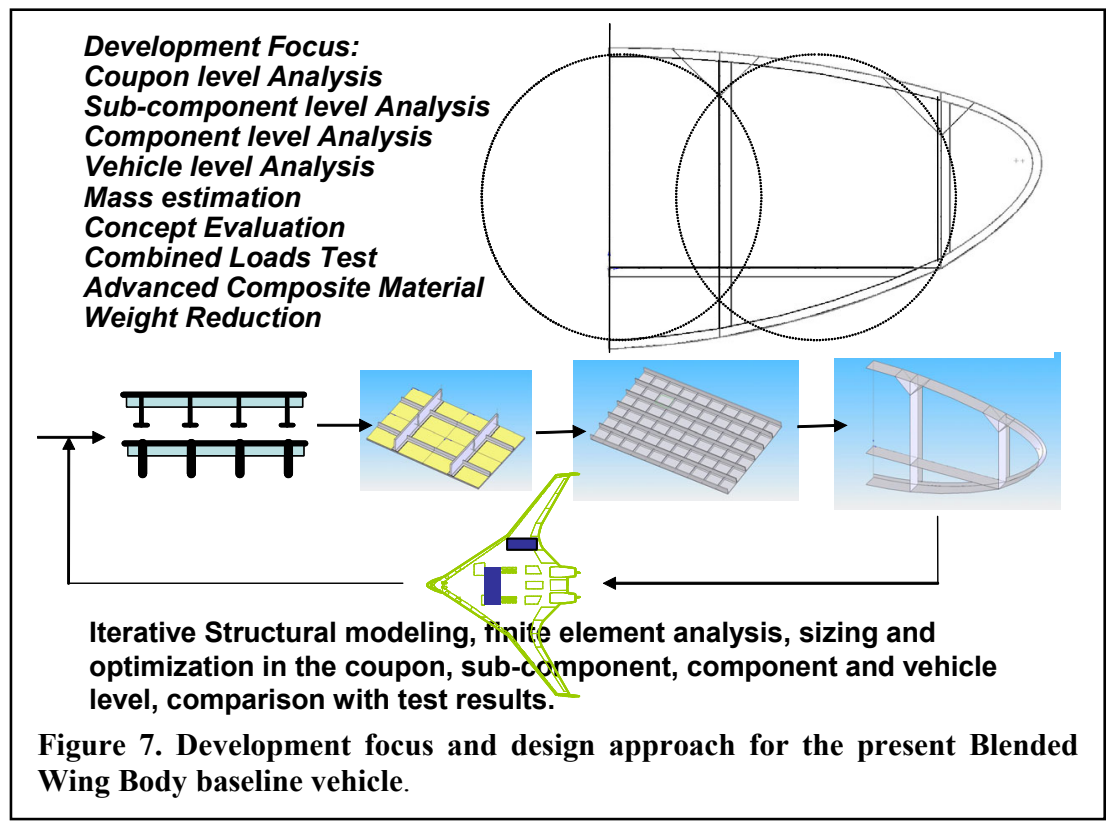
configuration was chosen, with highest consideration given to the unitized manufacturing and durability. This integrated design process is presently being applied to this new BWB baseline vehicle, under the Subsonic Fixed Wing (SFW) project, in the Fundamental Aeronautics Program. Figure 7 shows the development focus and design approach for the present BWB baseline vehicle. Detailed solid models of stitched composite panels at critical locations are being developed and analyzed. Test coupons and manufactured panels will be load tested, for comparison purposes. The design will be improved after each sizing exercise. For practical design consideration, Y braces are used (upper right sketch in Fig. 7) in the BWB pressurized fuselage in order to reduce the stress and deflection at the cabin-wall outer skin junctions. Locations of these $\mathrm{Y}$ braces may be used as geometric parameters for a configuration design investigation. These $\mathrm{Y}$ braces provide an engineering solution, in order to obtain the structural advantages of a multi-bubble concept ${ }^{22}$. The structural analysis of this concept is discussed in the next section.

\section{Multi-Bubble Fuselage}

For the BWB fuselage, an alternate multi-bubble structural configuration system was studied ${ }^{22,23}$. A multi-bubble or a multi-lobe configuration may provide certain structural advantages over straight walled pressure vessels. A summary of this concept analysis process and comparisons with conventional cylindrical and elliptic section fuselages are discussed in this section.

Baseline vehicle: The FEM model of an elliptic section A380 type fuselage section with two floors was used as the baseline configuration. This FEM analysis was compared with those of a cylindrical fuselage with the same circumference. FEM models of four multi-bubble concepts were developed and analyzed. Aluminum alloy plate (AL7050) material properties (see Table 1) were used for all six concepts.

Model development: Four FEM models were developed by merging the cylindrical concept to derive: 1) a double bubble section, 2) a three-bubble section, 3) a four-bubble section, and 4) a five-bubble section. The center distance between each segment was kept same as the radius so that the outer-skin and the inter-cabin wall junctions are at 120 degrees with each other (see Fig. 7). Theoretically, this equal-angle geometry provides a structural advantage, because of the membrane stress equilibrium at the bubble junctions where the outer shell meet the inter-cabin wall (see Fig. 8). The membrane stresses due to the internal cabin pressures, acting on the outer shell, are balanced by the inter-cabin wall tension.

Key Design Parameters: The shell element thicknesses were used as the key design parameters. The 7.75 meters (305.1 inch) diameter cylindrical section fuselage had same circumference as the 8.5 meters (334.6 inch) high, 7 meters $(275.6 \mathrm{inch})$ wide stiffened elliptic section fuselage. Both were stiffened with I section ring frames, at 0.5 meter (19.7 inch) interval. These $I$ section beam stiffeners, typical for a commercial transport aircraft, ${ }^{24,25}$ were used on all outer skins, inter-cabin walls and floors.

Design loads: The cylindrical and elliptical fuselages were subjected to $18.6 \mathrm{psi}$ internal pressure load. The twobubble and three-bubble sections were also subject to 18.6 psi internal pressure load. For the four-bubble and fivebubble structures, a combined 12.4 psi internal pressure and bending load condition were added. The bending load was represented by a $9200 \mathrm{lbs} / \mathrm{inch}$ compression (C) running load at the top and at a $9200 \mathrm{lbs} / \mathrm{inch}$ tension (T) 
running load at the bottom (see Fig. 10). Double skin ribbed shells were added at the top and bottom of the fourbubble and five-bubble concepts in order to withstand these additional loads.

Finite element analysis: In this study, the key design parameters were kept same for all configurations. Combined loading cases and suitable structures were added to derive each subsequent multi-bubble concept. The FEM analysis was performed to ensure that the maximum von-Mises stresses were well below the allowable yield stress. The objective was to demonstrate the validity of the assumed stress-balancing concept, and show that the multi-bubble

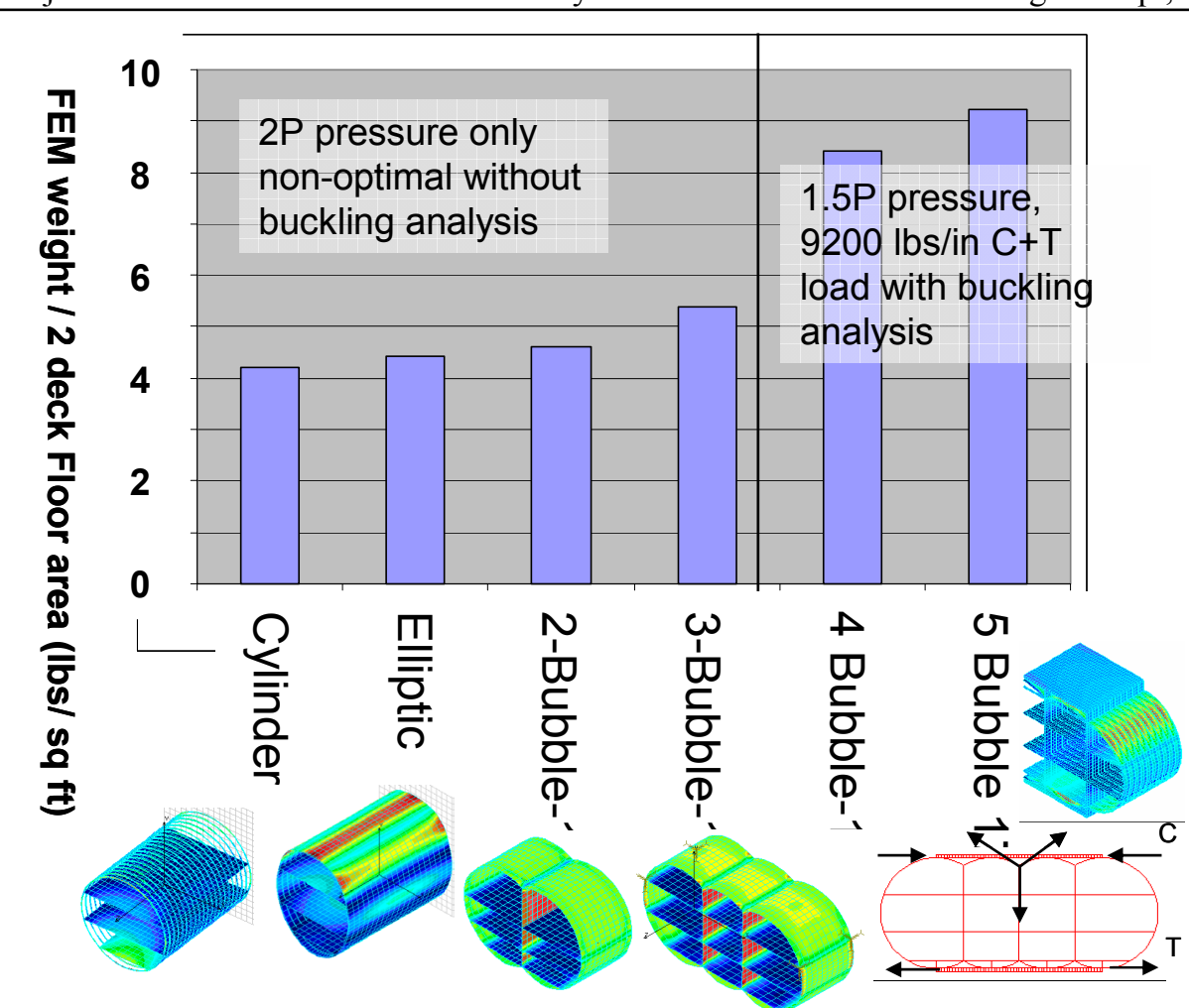

Figure 8. Structural unit-weight growth and relative weight/floor-area comparison. configuration would have acceptable stress levels and deflections under similar loading conditions. It was noted that the maximum tensile stresses occurred on the inter-cabin walls for the 2-bubble and 3-bubble sections. Figure 8 shows the structural unit-weight associated with each concept. The unit-weight was defined as the ratio of the FEM-weight/total-floorarea. Since, each concept had different overall dimension, the structural weight of each finite element model was divided by its total floor area for a reasonable comparison. The ratio of the FEMweight/floor-area is shown to increase from $4 \mathrm{lbs} / \mathrm{ft}^{2}$ for the cylinder to over 9 $\mathrm{lbs} / \mathrm{ft}^{2}$ for the five-bubble section. However, it should be cautioned that the as-

built weight of an airframe is significantly higher than the FEM weight. This is due to the added reinforcements, which are usually not modeled in a FEM analysis at the conceptual level. Generally for a typical metal airframe, multiplication factors ranging from 1.7 to 2.0 are used in order to estimate the as-built weight from the FEM weight.

\section{Crew Exploration Vehicle}

Figure 9 shows a notional Crew Exploration Vehicle (CEV) system ${ }^{2}$ assembly consisting of the Command Module (CM), Service Module (SM), Launch Abort System (LAS), Heat Shield (HS), Inter-Stage Rings (ISR), and the Earth Departure Stage (EDS). The Command Module (CM) is a scaled up version of the Apollo Command Module, which had a base diameter of 3.91 meters (12.83 feet). The Apollo Command Module's inner pressure vessel structure was an aluminum sandwich consisting of a welded aluminum inner skin, a thermally bonded honeycomb core, and a thin aluminum face sheet. The central compartment structure consisted of an inner aluminum face sheet with a steel honeycomb core. The aft heat shield consisted of four brazed honeycomb panels, four spotwelded sheet metal fairings, and a circumferential ring. The steel honeycomb core and outer face sheets were thermally bonded to the inner skin. The forward compartment was separated from the central part by a bulkhead and was supported by four 90 -degree wedges. 


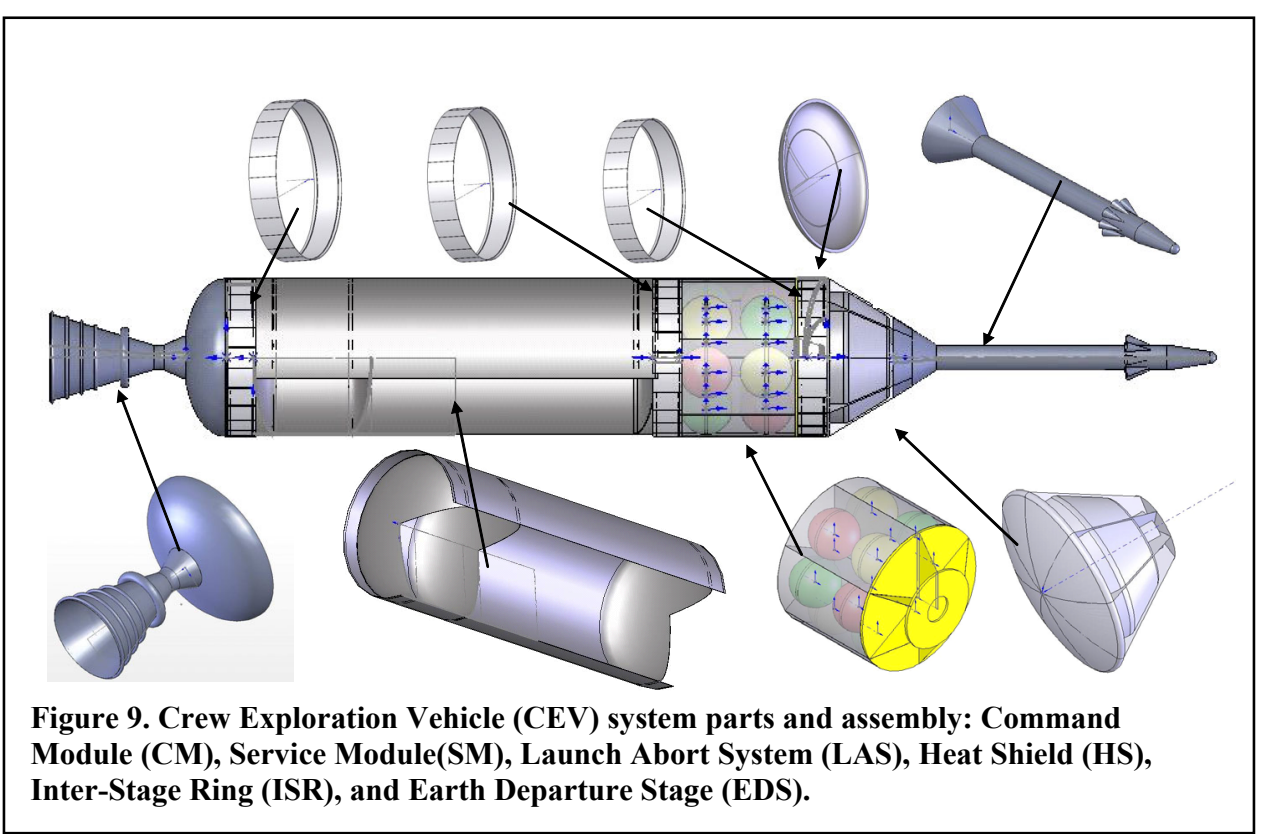

Baseline vehicle model: The general description and mass estimation of the CEV system were reported in the NASA space exploration system architecture report ${ }^{2}$. The CEV components were modeled as axisymmetric bodies of revolution. Figure 10 shows the major dimensions of the CM, and two solid models, in the first row. The CM outer base was assumed to be 5.5 meters (216.5 inches) in diameter. The outer base diameter and the overall length of the

$\mathrm{CM}$ were related to provide a specific cone angle. The solid models show the inner and outer shells along with the four major spars and the exit tunnel. The next split-solid model shows the major cutouts in the outer shell. The four spars transfer the impulsive thrust load to the primary structure, if the launch abort rocket is activated. A basic cross section of the CM was used to create a series of solid and surface models for the finite element analysis. The second row in Fig. 10 shows the surface models of the inner and outer shells. Four spars were placed at 90 degrees interval, in the gap between the inner and outer shell. Preliminary structural analysis results of the solid models were reported
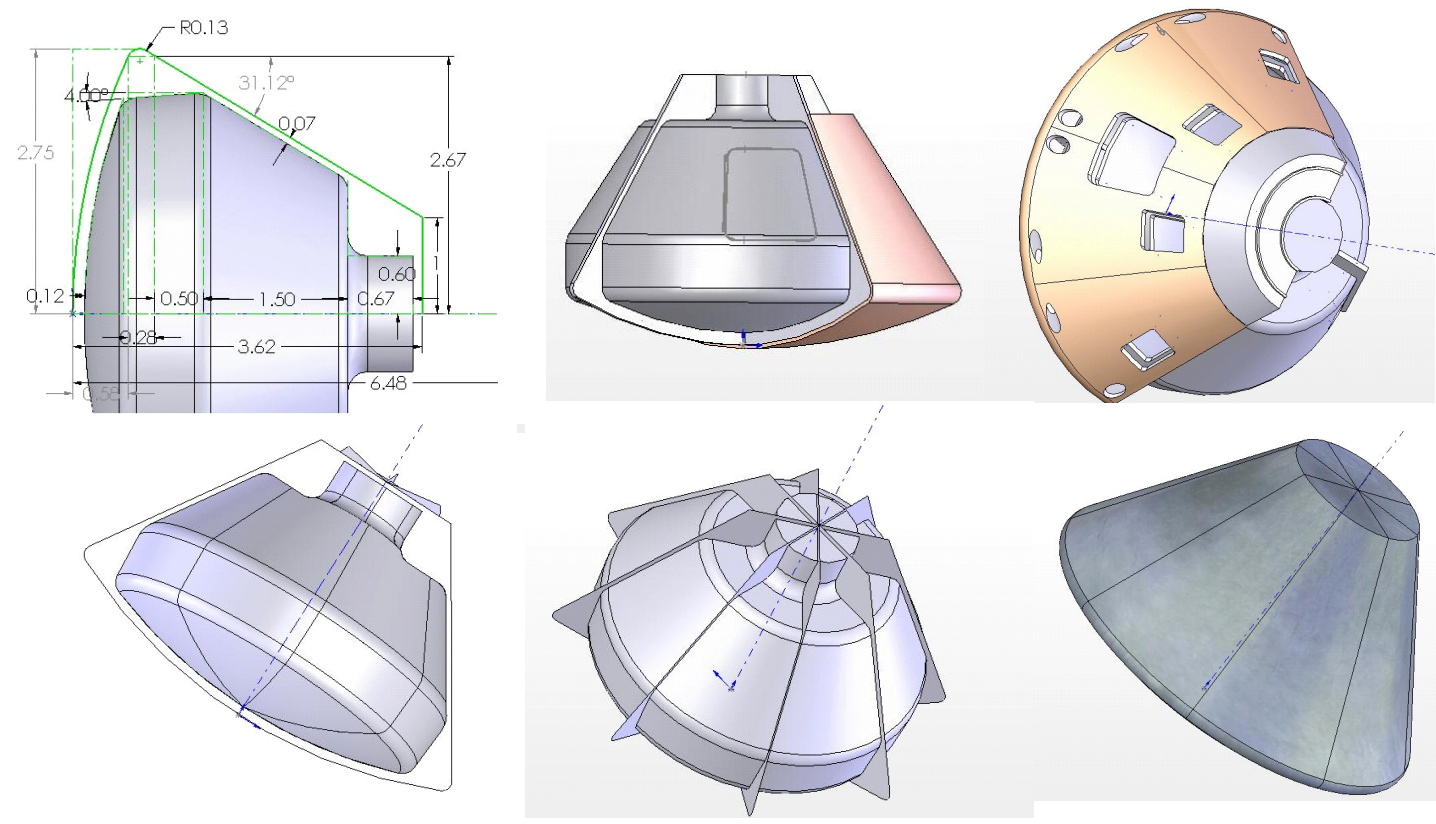

Figure 10. Solid and surface models with structural layout of a notional command module

in Ref. 26. These models were improved ${ }^{27}$ with 0.2 meters $(7.87$ inch) radius fairing at all the corners of the inner shell, in order to reduce the stresses at these junctions. Guided by these initial solid model stress analyses, the surface models were created with faired outer and inner mold lines. In order to reduce the stress and deformation due the internal pressure, four more spars were added in between the main four spars at 45 degrees interval. 
CEVGc 3.Shel1:: Static Nodal Stress Top
Units: psi Deformation Scale $1: 1$

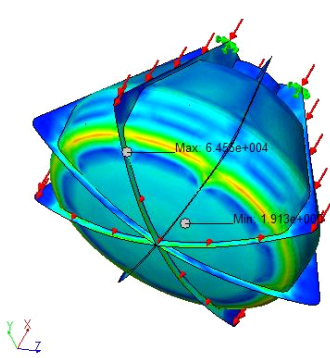

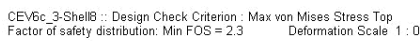
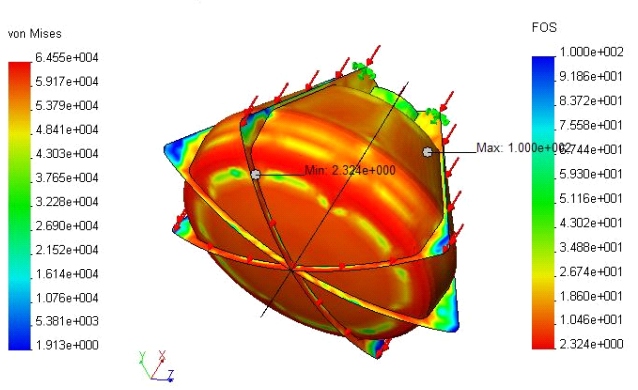

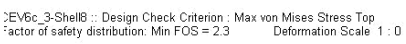

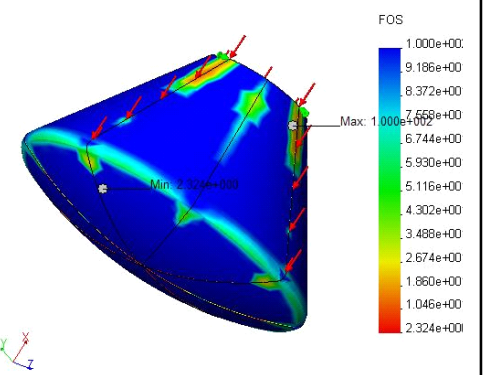

Figure 11. Von-Mises stress distributions and the ratio of the von-Mises stress/yield stress from the finite element analysis case 4 (Table 2).

Design loads: In the NASA Procedural Requirement document NPR 8705.2A, the minimum factor of safety for a human rated mission is specified to be 2.0. The NPR $8705.2 \mathrm{~A}$ also specifies a 1.5 factor of safety on burst pressure for fluid pressure vessels; a 1.4 ultimate factor of safety on all new or redesigned structures; and a 1.25 factor of safety on proof pressure for fluid pressure vessels. The CM internal cabin design pressure is assumed to be 14.7 psi. In addition, a 320,000 lbs axial force is applied on the four primary spars to represent the launch abort thrust force. The ascent aerodynamic pressure, reentry and landing impact loads were not considered in this limited study.

Design parameter and material selection: The thicknesses of the inner and outer shells and the axial spars were used as key design parameters. A combination of the Aluminum alloy (AL7050-T73651) and Titanium alloy (Ti4A16V) materials were considered for the inner and outer shells. These material properties are shown in Table 1 in the Appendix.

Finite element analysis and sizing: A summary of the FEM analysis and five sizing studies are presented in Table 2. Figure 11 shows the von-Mises stress distribution from the analysis case 4 . In the first case, the outer shell was assumed to be made of $20 \mathrm{~mm}(0.787 \mathrm{inch})$ thick Titanium alloy (Ti6AL4V). The inner shell was assumed to be 10 $\mathrm{mm}(0.393 \mathrm{inch})$ thick and the spars were $20 \mathrm{~mm}$ thick AL7050-T736 alloy plates. Total FEM mass was estimated to

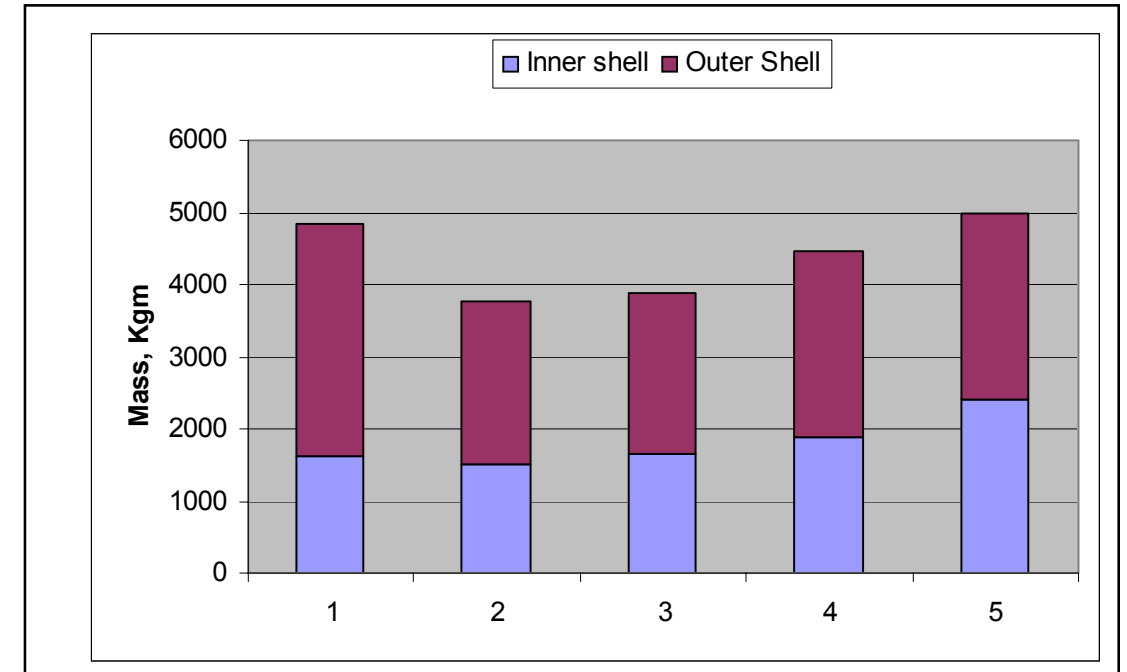

Figure 12. Mass comparison of $\mathrm{CM}$ inner and outer shells for the five design cases with the cabin pressure and abort thrust loads: 1) $10 \mathrm{~mm}$ AL 7050 inner shell, 20 mm AL7050 spars, 10 mm Ti6Al4V outer shell; 2) $5 \mathrm{~mm}$ inner shell and spars, $7 \mathrm{~mm}$ outer shell (Ti6Al4V); 3) $5 \mathrm{~mm}$ inner shell, $8 \mathrm{~mm}$ spars, $7 \mathrm{~mm}$ outer shell (Ti6Al4V); 4) $6 \mathrm{~mm}$ inner shell, $8 \mathrm{~mm}$ spars, and outer shell (Ti6Al4V); and 5) $8 \mathrm{~mm}$ inner shell, spars, and outer shell (Ti6Al4V). for this case. Since the maximum stress areas of the inner shell were at the cone-cylinder junction and along the sparshell junctions, additional reinforcements may be necessary to reduce these local stresses. In the fifth design, from manufacturing considerations, all the shell and spars were assumed to be made of $8 \mathrm{~mm}$ thick Titanium alloy plate. In 
this case the minimum safety margin was 2.4 , with the combined pressure and launch abort loads, but the total mass increased to $4987 \mathrm{~kg}$ (10994 lbs).

Mass comparison: Figure 12 shows the CM mass comparison for the five design cases, with the cabin pressure and abort thrust loads: 1) $10 \mathrm{~mm}$ thick AL7050 inner shell, $20 \mathrm{~mm}$ thick AL7050 spars, and $10 \mathrm{~mm}$ thick Ti6Al4V outer shell, 2) $5 \mathrm{~mm}$ thick inner shell and spars, and $7 \mathrm{~mm}$ thick outer shell (Ti6Al4V), 3) $5 \mathrm{~mm}$ thick inner shell, 8 $\mathrm{mm}$ thick spars, and $7 \mathrm{~mm}$ thick outer shell (Ti6Al4V), 4) $6 \mathrm{~mm}$ thick inner shell, $8 \mathrm{~mm}$ thick spars and outer shell (Ti6Al4V), and 5) $8 \mathrm{~mm}$ thick inner shell, spars, and outer shell (Ti6Al4V). Although the minimum margin of safety requirements are met for these limited load conditions, additional design investigations are necessary with the thermal and landing loads. Initial thermal load studies indicate that the structural mass is likely to escalate further.

\section{HALE Vehicle}

An initial baseline High Altitude Long Endurance (HALE) vehicle design and technical requirements were described in Ref. 10. In order to satisfy the long endurance requirements, a large aspect ratio wing was required. This wing had a very large aspect ratio of 29 and an area of 200 square meters.

Baseline vehicle: The internal structural layout process of the baseline vehicle was described in Ref. 14. The AML/AMRAVEN ${ }^{17}$ software was used for this layout. The IGES file of the structural layout was converted to ParaSolid format using SolidWorks ${ }^{19}$. Both the PATRAN/NASTRAN ${ }^{18}$ and the CosmosWorks ${ }^{20}$ software were used for the meshing and FEM analysis. The internal structural layout of this vehicle is shown in Figure 13.

Design loads: For this long 38.1 meter semi-span straight wing, an elliptic load distribution was assumed. The wing design load distribution values at 15 span-wise stations are shown in Table 3 . The ultimate design loads were computed for a straight wing at the $2.5 \mathrm{~g}$ pull up maneuver with a MTGW of $2828 \mathrm{~kg}$ (6235 lbs). Figure 13 shows the bar plot of this elliptic discrete load distribution. For application of the design loads onto the FEM model, each discrete load was divided by the average segment area, and was applied as uniform pressure on that segment.

Alternatively, one can use CosmosFlow $^{20}$ software capability to compute the aerodynamic pressure distribution on the wing outer mold line (see Figure 3). The interpolated aerodynamic load matrix can then be applied to the FEM model grid. Inclusion of this feature into the design process of future unconventional vehicles would be a significant improvement in the present capability.

Key design variables: For the wing analysis, the primary design variables are material properties and shell element thicknesses. The sizing study used aluminum alloy AL7075 and SRFI advanced composite material properties ${ }^{12}$, as shown in Table 1.
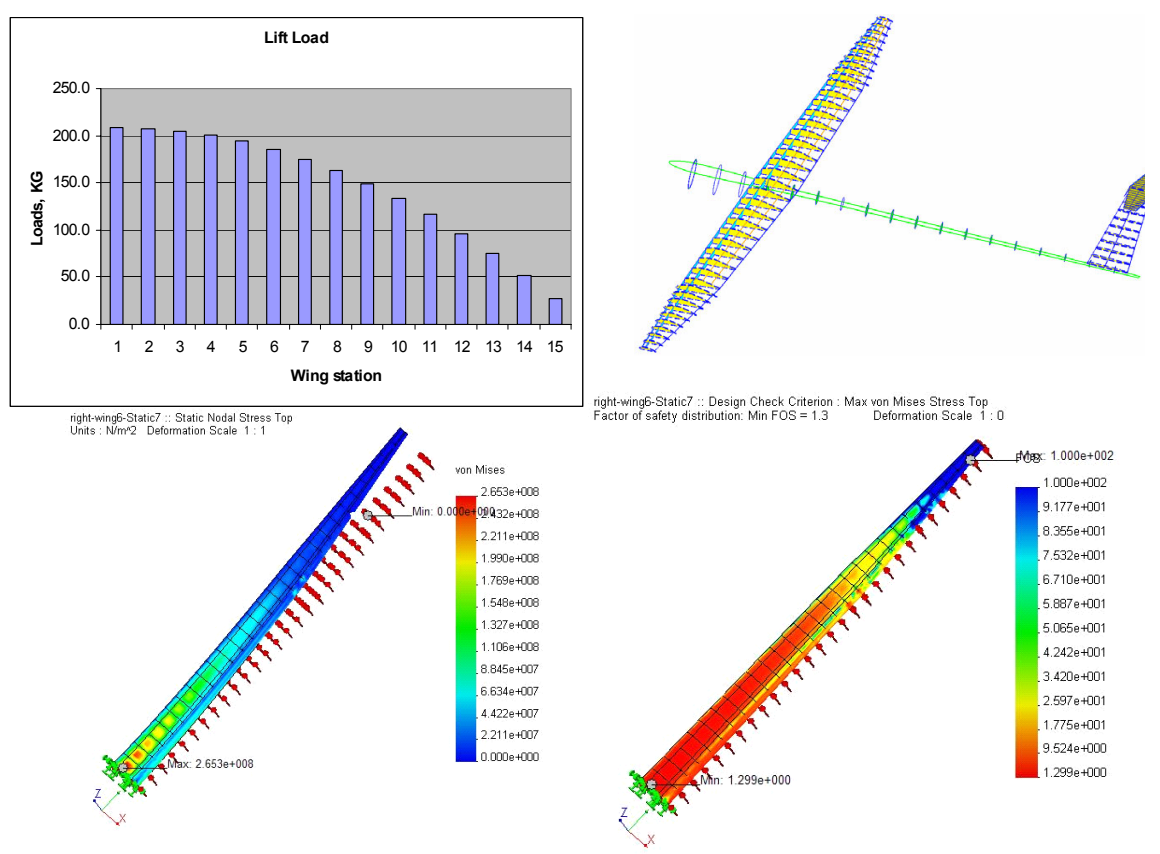

Figure 13. HALE vehicle structural layout, wing loading, von-Mises stress and margins of safety distribution at a $2.5 \mathrm{~g}$ pull up condition at the maximum take off gross weight.

Finite element analysis: Table 4 shows weight contributions of each of the structural component group, maximum stress, deflections, and the minimum safety margins from the FEM analysis and sizing study. The minimum safety margin was based on the ratio of the material yield stress/maximum von-Mises Stress. For the aluminum wing, the minimum wing weight was $1177 \mathrm{~kg}(2593 \mathrm{lbs})$. Although the minimum margin of safety was 1.45 , the minimum gage thickness of $1 \mathrm{~mm}(0.039 \mathrm{inch})$ was reached, and the maximum tip deflection was 6.6 meters. The tip deflection was 5.3 meters. By using the advanced composite SRFI material properties, the wing weight was reduced to $542 \mathrm{~kg}(1194 \mathrm{lbs})$ with a minimum safety margin of 1.3 . The distribution of the von-Mises 
stresses and margins of safety, for this case, are also shown in Figure 13. However, the minimum SRFI stack thickness was $1.32 \mathrm{~mm}(0.052 \mathrm{inch})$. With this thickness value, the wing weight was $547 \mathrm{~kg}$ (1205 lbs), and the minimum safety margin was 1.16 . Since the total wing FEM weight fraction was near $39 \%$ of the design MTGW, this vehicle design may be infeasible. Alternatively, a lighter wing may be designed if the vehicle is restricted to less severe pull up maneuver load.

\section{Conclusion}

Using examples of a blended-wing-body fuselage, a multi-bubble fuselage concept, a conceptual crew exploration vehicle, and a high altitude long endurance aircraft, an efficient structural model development and design process is presented. Integrated multi-disciplinary tools were used for generating parametric geometry, and internal structural layout of the vehicle and components that facilitated rapid finite element analysis, sizing study and weight estimation. The parametric modeling features allowed for quick exploration of the design space by changing important design parameters. Detailed finite element models were developed and analyzed, not only to arrive at a feasible structural configuration, but also to provide a higher fidelity method of structural mass estimation. The blended-wing-body structural analysis may lead to a better structural configuration for the present baseline vehicle. The notional crew capsule structural analysis indicated high stress areas, which may require significant redesign. The large aspect ratio wing analysis indicated that significant weight reduction is possible with advanced composite material. However, since the structural weight fraction is still quite high, this design may be infeasible. The wing must be restricted to a much reduced pull-up maneuver loads. From these lessons learned, the vehicle structural concept can be improved. This integrated process is presently being used for the Blended Wing Body vehicle structural design under the Subsonic Fixed Wing project in the areas of advanced composite materials and structures. These integrated software tools and processes may significantly improve the existing conceptual design capability, and facilitate the physics-based systems analysis process.

\section{Appendix}

\begin{tabular}{|c|c|c|c|c|c|c|}
\hline Material Type & Physical Properties & prop symbc & unit & psi & $\mathrm{kg} / \mathrm{cm} / \mathrm{cm}$ & $\mathrm{N} / \mathrm{m} 2$ (Pascals) \\
\hline AL7050-Ti Metal & Young's Mudulus & EX & \multirow{7}{*}{$\mathrm{lb} /$ cuin } & $1.03000 \mathrm{E}+07$ & $7.24174 \mathrm{E}+05$ & $7.10415 \mathrm{E}+10$ \\
\hline \multirow[t]{6}{*}{ plate } & Poisson's ratio & NUXY & & 0.33 & & \\
\hline & Shear Modulus & GXY & & $3.87218 \mathrm{E}+06$ & $2.72246 \mathrm{E}+05$ & $2.67073 E+10$ \\
\hline & Density & DENS & & 0.10200 & 0.002823398 & 2823.397773 \\
\hline & UltimateTensile Strength & SIGXT & & $7.10000 E+04$ & $4.99188 E+03$ & $4.89703 E+08$ \\
\hline & Ultimate Compressive Strength & SIGXC & & $6.00000 E+04$ & $4.21849 E+03$ & $4.13834 \mathrm{E}+08$ \\
\hline & Yield Strength & SIGYLD & & $6.20000 E+04$ & $4.35910 \mathrm{E}+03$ & $4.27628 \mathrm{E}+08$ \\
\hline Material type & Physical Properties & propsymbo & unit & psi & $\mathrm{kgf} / \mathrm{cm} / \mathrm{cm}$ & $\mathrm{N} / \mathrm{m} 2$ (Pascals) \\
\hline AL-6061 T metal & Young's Mudulus & EX & \multirow{7}{*}{$\mathrm{lb} /$ cuin } & $9.90 \mathrm{E}+06$ & $6.96051 \mathrm{E}+05$ & $6.82826 \mathrm{E}+10$ \\
\hline \multirow[t]{6}{*}{ plate } & Poisson's ratio & NUXY & & 0.33 & & \\
\hline & Shear Modulus & GXY & & $3.72180 \mathrm{E}+06$ & $2.61673 E+05$ & $2.56701 \mathrm{E}+10$ \\
\hline & Density & DENS & & 0.098 & 0.002712676 & 2712.676291 \\
\hline & UltimateTensile Strength & SIGXT & & $4.20000 E+04$ & $2.95294 \mathrm{E}+03$ & $2.89684 \mathrm{E}+08$ \\
\hline & Ultimate Compressive Strength & SIGXC & & $3.50000 E+04$ & $2.46078 \mathrm{E}+03$ & $2.41403 E+08$ \\
\hline & Yield Strength & SIGYLD & & $3.60000 \mathrm{E}+04$ & $2.53109 \mathrm{E}+03$ & $2.48300 \mathrm{E}+08$ \\
\hline Material type & Physical Properties & \multicolumn{2}{|c|}{ propsymbol unit } & psi & $\mathrm{kg} / \mathrm{cm} / \mathrm{cm}$ & $\mathrm{N} / \mathrm{m} 2$ (Pascals) \\
\hline Ti6AL4VA metal & Young's Mudulus & EX & \multirow{7}{*}{$\mathrm{lb} /$ cuin } & 16000000 & $1.12493 \mathrm{E}+06$ & $1.10356 \mathrm{E}+11$ \\
\hline \multirow[t]{6}{*}{ plate } & Poisson's ratio & NUXY & & 0.33 & \multicolumn{2}{|r|}{0.33} \\
\hline & Shear Modulus & GXY & & $6.01504 \mathrm{E}+06$ & $4.22906 \mathrm{E}+05$ & $4.14871 \mathrm{E}+10$ \\
\hline & Density & DENS & & 0.162 & 0.004555968 & 4484.219992 \\
\hline & UltimateTensile Strength & SIGXT & & 160000 & $1.12493 \mathrm{E}+04$ & 1.10356E+09 \\
\hline & Ultimate Compressive Strength & SIGXC & & 145000 & 1.01947E+04 & $1.00010 \mathrm{E}+09$ \\
\hline & Yield Strength & SIGYLD & & 150000 & $1.05462 \mathrm{E}+04$ & $1.03458 \mathrm{E}+09$ \\
\hline Material type & Physical Properties & \multicolumn{2}{|c|}{ propsymbol unit } & psi & $\mathrm{kgf} / \mathrm{cm} / \mathrm{cm}$ & N/m2 (Pascals) \\
\hline \multirow{5}{*}{$\begin{array}{l}\text { ACT-stitch composite } \\
\text { ACT wing laminated mate } \\
\text { ACT-stitched RFI Advance } \\
\text { Use for variable thickness } \\
\text { Average property }\end{array}$} & Flexural Modulus- $X$ & \multicolumn{2}{|c|}{ EX } & 9250000 & $6.50350 \mathrm{E}+05$ & $6.37994 \mathrm{E}+10$ \\
\hline & IFlexural Modulus- $Y$ & \multicolumn{2}{|l|}{$\mathrm{EY}$} & 4650000 & $3.26933 E+05$ & $3.20721 E+10$ \\
\hline & €Poisson's ratio & NUXY & & 0.397 & 0.397 & 0.397 \\
\hline & Shear Modulus- $X Y$ & GXY & & 2270000 & $1.59599 \mathrm{E}+05$ & $1.56567 E+10$ \\
\hline & Density & DENS & $\mathrm{lb} /$ cuin & 0.057 & 0.001603026 & 1577.781108 \\
\hline & Tensile Strength, Ultimate-av & SIGXT & & 50000 & $3.51541 \mathrm{E}+03$ & $3.44861 \mathrm{E}+08$ \\
\hline & Compressive Strength, Ultimate & SIGXC & & 38000 & $2.67171 \mathrm{E}+03$ & $2.62095 \mathrm{E}+08$ \\
\hline & Yield Strength-AV & SIGYLD & & 44000 & $3.09356 \mathrm{E}+03$ & $3.03478 \mathrm{E}+08$ \\
\hline Material type & Physical Properties & propsymbo & unit & English(psi) & $\mathrm{kgf} / \mathrm{cm} / \mathrm{cm}$ & $\mathrm{N} / \mathrm{m} 2$ (Pascals) \\
\hline Phenolic 3 composite & Flexural Modulus & EX & & $1.17 \mathrm{E}+06$ & $8.22605 \mathrm{E}+04$ & $8.06976 \mathrm{E}+09$ \\
\hline Phenolic - "91LD". Graphit & tPoisson's ratio & NUXY & & 0.2000 & 0.2000 & 0.2 \\
\hline Subcategory: Carbon Fibe & Density & DENS & $\mathrm{lb} /$ cuin & $0.0502 \mathrm{lb} / \mathrm{in}^{3}$ & $1.39 \mathrm{~g} / \mathrm{cc}$ & 1390 kg/Mcube \\
\hline Phenolic 37\%, Graphite fa & Shear Modulus-XY & GXY & & 487500 & $3.42752 E+04$ & 3.36240E+09 \\
\hline & Tensile Strength, Ultimate & SIGXT & & 19970 & $1.40405 \mathrm{E}+03$ & $1.37738 \mathrm{E}+08$ \\
\hline & Flexural Yield Strength & SIGYLD & & 17800 & $1.25148 \mathrm{E}+03$ & $1.22771 \mathrm{E}+08$ \\
\hline & Coeff Thermal expansion & ALPX & & 6.0 e-6 in/in- ${ }^{\circ} \mathrm{F}$ & & $12.0 \mathrm{e}-6 \mathrm{~m} / \mathrm{m}-{ }^{\circ} \mathrm{C}$ \\
\hline & Thermal conductivity & $\mathrm{KX}$ & btu/in-s-F & 0.001929012 & & $110 \mathrm{~W} / \mathrm{m}-\mathrm{K}$ \\
\hline & Specific Heat & $\mathrm{C}$ & & $0.25 \mathrm{BTU} / \mathrm{lb}-{ }^{\circ} \mathrm{F}$ & & 1100 Joules/Kg \\
\hline
\end{tabular}

Table 1. Material properties used in the FEM analysis of the four examples. 


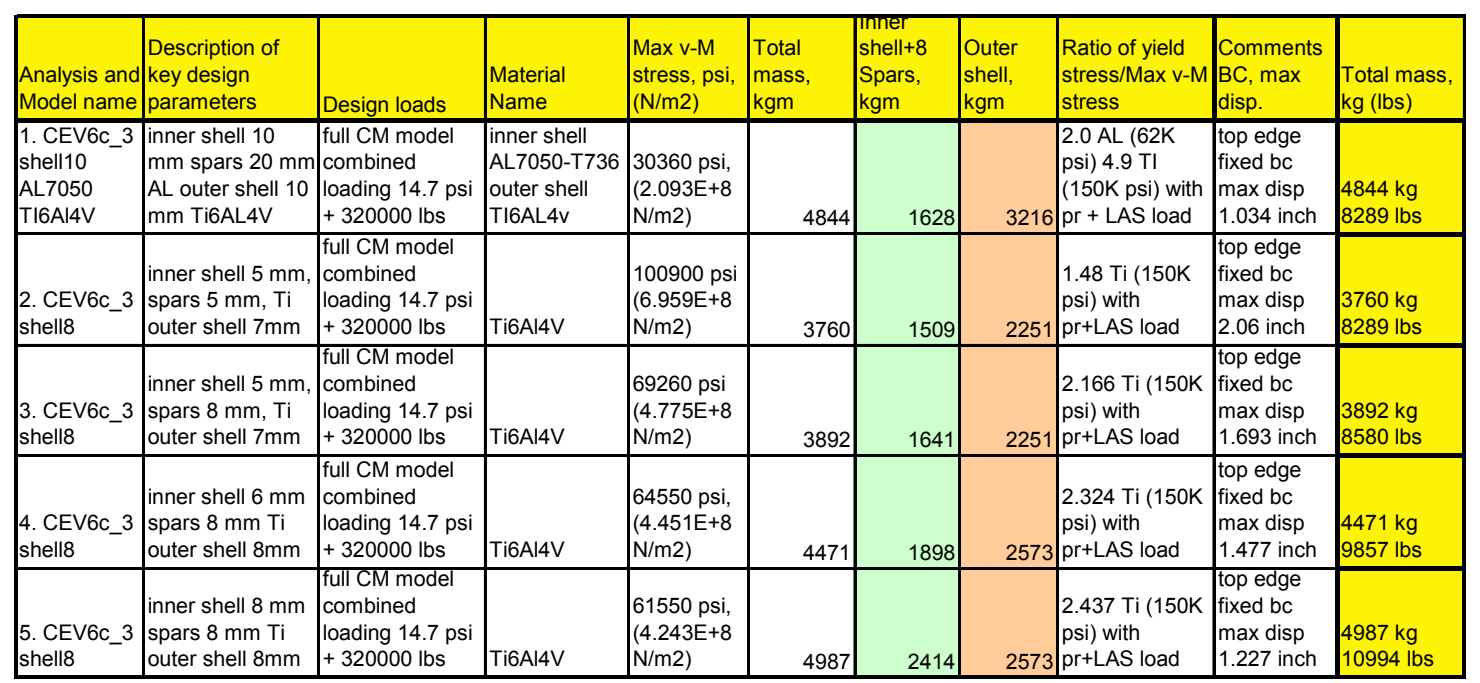

Table 2. Summary of structural analysis results for a notional Command Module concept.

\begin{tabular}{|c|c|c|c|c|c|c|c|c|c|c|c|}
\hline & xloc & yloc & zloc lift load & & shear & $\begin{array}{l}\text { bending } \\
\text { moment }\end{array}$ & $\begin{array}{l}\text { torsion } \\
\text { moment }\end{array}$ & $\begin{array}{l}\text { av panel } \\
\text { pressure }\end{array}$ & & load & \\
\hline root & 0 & 0 & 0 & 208.8 & 5302.5 & & & N/Sqm & kgf/Sqm & psi & psf \\
\hline 1 & 0 & $\overline{0}$ & $\overline{0}$ & 208.8 & 416.6 & 93948.5 & 0.0 & 343.10 & 34.97 & 0.0497 & 7.16 \\
\hline 2 & 2.54 & 0 & 0 & 207.8 & 412.9 & 79134.5 & 0.0 & 341.57 & 34.82 & 0.0495 & 7.13 \\
\hline 3 & 5.08 & 0 & 0 & 205.0 & 405.5 & 65501.2 & 0.0 & 337.00 & 34.35 & 0.0489 & 7.04 \\
\hline 4 & 7.62 & 0 & 0 & 200.4 & 394.3 & 53142.8 & 0.0 & 329.37 & 33.58 & 0.0478 & 6.88 \\
\hline 5 & 10.16 & 0 & 0 & 193.9 & 379.5 & 42125.4 & 0.0 & 318.70 & 32.49 & 0.0462 & 6.65 \\
\hline 6 & 12.7 & 0 & 0 & 185.6 & 360.9 & 32486.7 & 0.0 & 304.97 & 31.09 & 0.0442 & 6.37 \\
\hline 7 & 15.24 & 0 & 0 & 175.4 & 338.7 & 24236.0 & 0.0 & 288.20 & 29.38 & 0.0418 & 6.02 \\
\hline 8 & 17.78 & 0 & 0 & 163.3 & 312.7 & 17354.5 & 0.0 & 268.38 & 27.36 & 0.0389 & 5.60 \\
\hline 9 & 20.32 & 0 & 0 & 149.4 & 283.0 & 11795.1 & 0.0 & 245.50 & 25.03 & 0.0356 & 5.13 \\
\hline 10 & 22.86 & 0 & 0 & 133.6 & 249.6 & 7482.4 & 0.0 & 219.58 & 22.38 & 0.0318 & 4.58 \\
\hline 11 & 25.4 & 0 & 0 & 116.0 & 212.5 & 4312.7 & 0.0 & 190.61 & 19.43 & 0.0276 & 3.98 \\
\hline 12 & 27.94 & 0 & 0 & 96.5 & 171.6 & 2154.0 & 0.0 & 158.59 & 16.17 & 0.0230 & 3.31 \\
\hline 13 & 30.48 & 0 & 0 & 75.2 & 127.1 & 846.0 & 0.0 & 123.51 & 12.59 & 0.0179 & 2.58 \\
\hline 14 & 33.02 & 0 & 0 & 52.0 & 78.9 & 200.3 & 0.0 & 85.39 & 8.70 & 0.0124 & 1.78 \\
\hline 15 & 35.56 & 0 & 0 & 26.9 & 26.9 & 0.0 & 0.0 & 44.22 & 4.51 & 0.0064 & 0.92 \\
\hline
\end{tabular}

Table 3. Wing design loads at a 2.5 g pull up maneuver with MTGW of $2828 \mathrm{~kg}$.

\begin{tabular}{|c|c|c|c|c|c|c|c|c|c|}
\hline \multirow[t]{2}{*}{$\begin{array}{l}\text { HALE WING } \\
\text { MTGW } 2828 \text { kg }\end{array}$} & & \begin{tabular}{l}
\multicolumn{1}{c}{ ell } \\
thickness \\
wing
\end{tabular} & \begin{tabular}{l}
\multicolumn{1}{c}{ ell } \\
thickness \\
TE
\end{tabular} & $\begin{array}{l}\text { ell } \\
\text { thickness } \\
\text { ribs\&spars }\end{array}$ & \begin{tabular}{|l} 
Total \\
Weight
\end{tabular} & $\begin{array}{l}\text { Max tip } \\
\text { deflection }\end{array}$ & \multirow{2}{*}{$\begin{array}{l}\text { Miax von- } \\
\text { Mises } \\
\text { stress } \\
\text { top } \\
\text { surface }\end{array}$} & \multirow{3}{*}{\begin{tabular}{|l}
$\begin{array}{l}\text { Ratio of } \\
\text { yield } \\
\text { stress/ }\end{array}$ \\
V-Mises \\
stress
\end{tabular}} & \multirow[t]{3}{*}{ comments } \\
\hline & Study name & Sheet 1 & Sheet-2 & Sheet 3-188 & $\mathrm{kg}$ & meters & & & \\
\hline $\begin{array}{l}\text { Material name } \\
\text { Density }\end{array}$ & Units --> & $\mathrm{mm}$ & $\mathrm{mm}$ & $\mathrm{mm}$ & (pounds) & \begin{tabular}{|l} 
inch \\
weight(Ibs)
\end{tabular} & $\mathrm{N} / \mathrm{m} 2(\mathrm{psi})$ & & \\
\hline $\begin{array}{l}\text { AL-7075T73651 } \\
0.102 \mathrm{lb} / \text { inch3 }\end{array}$ & $\begin{array}{l}\text { right-wing-shell1 } \\
\text { wt kg } \\
\text { wt lbs }\end{array}$ & $\begin{array}{l}3 \mathrm{~mm} \\
1347 \\
2962 \\
\end{array}$ & $\begin{array}{l}2 \mathrm{~mm} \\
290 \\
640 \\
\end{array}$ & $\begin{array}{l}2 \mathrm{~mm} \\
268 \\
597\end{array}$ & $\begin{array}{l}1905 \mathrm{~kg} \\
1905 \\
4199 \\
\end{array}$ & $\begin{array}{l}1.97 \mathrm{~m} \\
77.5 \text { inch } \\
4199 \mathrm{lbs} \\
\end{array}$ & $\begin{array}{l}1.24 \mathrm{E}+08 \\
18010 \text { psi }\end{array}$ & 3.4000 & isotropic \\
\hline $\begin{array}{l}\text { AL-7075T73651 } \\
0.102 \mathrm{lb} / \text { inch3 }\end{array}$ & $\begin{array}{l}\text { right-wing-shell2 } \\
\text { wt kg } \\
\text { wt lbs }\end{array}$ & $\begin{array}{l}2.5 \mathrm{~mm} \\
1131 \\
2493\end{array}$ & $\begin{array}{l}1.5 \mathrm{~mm} \\
220 \\
485\end{array}$ & $\begin{array}{l}1.5 \mathrm{~mm} \\
377 \\
832\end{array}$ & $\begin{array}{l}1670 \mathrm{~kg} \\
1670 \\
3809\end{array}$ & $\begin{array}{l}2.353 \mathrm{~m} \\
71.5 \mathrm{inch} \\
3809 \mathrm{lbs}\end{array}$ & $19171 \mathrm{psi}$ & 3.2000 & isotropic \\
\hline $\begin{array}{l}\text { AL-7075T73651 } \\
0.102 \mathrm{lb} / \text { inch3 }\end{array}$ & $\begin{array}{l}\text { right-wing-shell3 } \\
\text { wt kg } \\
\text { wt lbs }\end{array}$ & $\begin{array}{l}1.5 \mathrm{~mm} \\
678 \\
1496\end{array}$ & $\begin{array}{l}1.5 \mathrm{~mm} \\
220 \\
485\end{array}$ & $\begin{array}{l}1.5 \mathrm{~mm} \\
377 \\
832\end{array}$ & $\begin{array}{l}1275 \mathrm{~kg} \\
1275 \\
2812\end{array}$ & $\begin{array}{l}2.818 \mathrm{~m} \\
85.7 \text { inch } \\
2812 \mathrm{lbs}\end{array}$ & $1.61 \mathrm{E}+08$ & 2.7000 & isotropic \\
\hline AL-7075T736 & $\begin{array}{l}\text { Shell } 7 \\
\text { wt kg } \\
\text { wt lbs }\end{array}$ & $\begin{array}{l}2 \mathrm{~mm} \\
898 \\
1975\end{array}$ & $\begin{array}{l}1 \mathrm{~mm} \\
145 \\
320 \\
\end{array}$ & $\begin{array}{l}1 \mathrm{~mm} \\
134 \\
299\end{array}$ & $\begin{array}{l}1177 \mathrm{~kg} \\
1177 \\
2593\end{array}$ & $\begin{array}{l}6.06 \mathrm{~m} \\
184 \text { inch } \\
2593 \text { lbs }\end{array}$ & $2.94 \mathrm{E}+08$ & 1.4500 & isotropic \\
\hline $\begin{array}{l}\text { SRFI-md97 } \\
0.058 \mathrm{lb} / \text { inch3 }\end{array}$ & $\begin{array}{l}\text { right-wing6-static6 } \\
\text { wt kg } \\
\text { wt lbs }\end{array}$ & $\begin{array}{l}2 \mathrm{~mm} \\
509 \\
1122\end{array}$ & $\begin{array}{l}1 \mathrm{~mm} \\
83 \\
182 \\
\end{array}$ & $\begin{array}{l}1 \mathrm{~mm} \\
77 \\
170 \\
\end{array}$ & $\begin{array}{l}669 \mathrm{~kg} \\
669 \\
1774 \mathrm{lbs} \\
\end{array}$ & $\begin{array}{l}4.02 \mathrm{~m} \\
158 \text { inch } \\
1174 \mathrm{lbs} \\
\end{array}$ & $\begin{array}{l}2.534 \mathrm{E}+8 \\
28500 \mathrm{psi}\end{array}$ & 1.7500 & $\begin{array}{l}\text { Orthotropic } \\
\text { Ex along span }\end{array}$ \\
\hline $\begin{array}{l}\text { SRFI-md97 } \\
0.058 \mathrm{lb} / \text { inch3 }\end{array}$ & $\begin{array}{l}\text { right-wing6-static7 } \\
\text { wt kg } \\
\text { wt lbs }\end{array}$ & $\begin{array}{l}1.5 \mathrm{~mm} \\
382 \\
842\end{array}$ & $\begin{array}{l}1.0 \mathrm{~mm} \\
82 \\
182\end{array}$ & $\begin{array}{l}1.0 \mathrm{~mm} \\
78 \\
170\end{array}$ & $\begin{array}{l}542 \mathrm{~kg} \\
542 \\
1194\end{array}$ & $\begin{array}{l}5.29 \mathrm{~m} \\
208 \text { inch } \\
1194 \mathrm{lbs}\end{array}$ & $\begin{array}{l}2.65 \mathrm{E}+08 \\
38480 \mathrm{psi}\end{array}$ & 1.3000 & $\begin{array}{l}\text { Orthotropic } \\
\text { Ex along span }\end{array}$ \\
\hline $\begin{array}{l}\text { SRFI-md97 } \\
0.058 \mathrm{lb} / \text { inch3 }\end{array}$ & $\begin{array}{l}\text { right-wing6-static8 } \\
\text { wt kg } \\
\text { wt lbs }\end{array}$ & $\begin{array}{l}1.32 \mathrm{~mm} \\
336 \\
741\end{array}$ & $\begin{array}{l}1.32 \mathrm{~mm} \\
109 \\
240\end{array}$ & $\begin{array}{l}1.32 \mathrm{~mm} \\
102 \\
224\end{array}$ & $\begin{array}{l}547 \mathrm{~kg} \\
547 \\
1205\end{array}$ & $\begin{array}{l}5.84 \mathrm{~m} \\
230 \text { inch } \\
1205 \mathrm{lbs}\end{array}$ & $\begin{array}{l}2.97 \mathrm{E}+08 \\
43100 \mathrm{psi}\end{array}$ & 1.1600 & $\begin{array}{l}\text { Orthotropic } \\
\text { Ex along span }\end{array}$ \\
\hline
\end{tabular}

Table 4. Summary of structural analysis results for the HALE vehicle wing. 


\section{Acknowledgments}

The author thanks Dr. Fayette Collier, Principal Investigator, Subsonic Fixed Wing Program; Karen Taminger Associate Principal Investigator (Materials and Structures); William Kimmel, Branch Head; Vincent Schultz, Assistant Branch Head; Aeronautical Systems Analysis Branch; Dr. John J. Rehder, SAIC, Dr. John Korte, Head, Vehicle Analysis Branch, Systems Analysis and Concepts Directorate, and the Fundamental Aeronautics Program Office for funding this research. Thanks are also due to Ronnie Gillian, Head, Advanced Engineering Environments Branch, Systems Engineering Directorate for providing the Integrated Design Center facility.

\section{References}

${ }^{1}$ Griffin, M. D., and French, J., R., "Space Vehicle Design,” 2nd Ed., AIAA Publication, Reston, VA, 1991, Chaps. 8, p.383

${ }^{2}$ NASA's Exploration Systems Architecture Study Final Report. NASA-TM-2005-214062, November 2005.

${ }^{3}$ Greenberg, H. S, "Structural Analysis Techniques for Preliminary Design of Launch vehicles," NASA Langley Short Course, Oct. 3-6, 2005.

${ }^{4}$ Roskam, J., “Airplane Design,” The DAR Corporation, Lawrence, Kansas, 2005.

${ }^{5}$ Aerospace Design Engineer's Guide, $5^{\text {th }}$ Edition. AIAA Publications, Reston, Virginia, September 2003.

${ }^{6}$ Raymer, D., Aircraft Design, A Conceptual Approach, $3^{\text {rd }}$ Ed. Przemieniecki, J. S. (Ed.), AIAA Educational Series, Reston, VA, 1999., Chap. 14, pp.403-416, Chap. 15, pp. 467-479.

${ }^{7}$ McCullers, A. Flight Optimization Systems Software (FLOPS) Release 5.91 User's Guide, NASA TM-1998-207644.

${ }^{8}$ Ardema, M., Chambers M., Patron, A. Hahn, A., Miura, H., and Moore, M., "Analytical Fuselage and Wing Weight Estimation of Transport Aircraft," NASA TM 110392, May 1996.

${ }^{9}$ Rocha, H., Li, W., and Hahn, A., "Principal Component Regression for Fitting Wing Weight Data of Subsonic Transports," Journal of Aircraft, Vol. 43, No. 6, Nov-Dec, 2006, pp. 1925-1936.

${ }^{10}$ Nickol, C. L., Guynn, M. D., Kohout, L. L., Ozoroski, T. L., "High Altitude Long Endurance Air Vehicle Analysis Alternatives and Technology Requirements Development, AIAA Paper 2007-1050.

${ }^{11}$ Conceptual Design of UAV Systems: University of Kansas Course Publication No. AA51530, 2005.

${ }^{12}$ Liebeck, R. H., Page, M. A., and Rawdon, B. K., "Blended-Wing-Body Subsonic Commercial Transport", AIAA Paper $98-$ 0438 .

${ }^{13}$ Liebeck, R. H., "Design of the Blended-Wing-Body Subsonic Transport", AIAA Paper 2002-0002.

${ }^{14}$ Mukhopadhyay, V., S-Y Hsu, B. H. Mason, M. D. Hicks, W. T. Jones, D. W. Sleight, J. Chu, J. L. Spangler, H. Kamhawi, and J. L. Dahl, " Adaptive Modeling, Engineering Analysis and Design of Advanced Aerospace Vehicles," AIAA Paper 20062182.

${ }^{15}$ ModelCenter: V.7 Basics and Analysis Server: User Manual, Phoenix Integration, Inc., Blacksburg, Virginia, URL: http://www.phoenix-int.com.

${ }^{16}$ Matlab/Simulink: Ver. 7.3 The MathWorks, Inc. Natick, MA. URL: http://www.mathworks.com.

${ }^{17}$ AML/AMRAVEN Basic User Manual: Ver. 4.11 TechnoSoft Inc. Cincinnati OH, URL: http://www.technosoft.com.

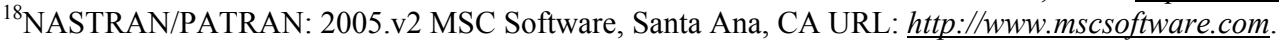

${ }^{19}$ SolidWorks, Ver. 2006, SolidWorks Corporation, Concord, MA URL: $\underline{\text { http://www.solidworks.com. }}$

${ }^{20}$ CosmosDesignStar/CosmosWorks/CosmosFloWorks: Ver. 2006 User Manuals, Structural Research and Analysis Corporation, Los Angeles, California, URL: http://www.cosmosm.com.

${ }^{21}$ NASA Website URL: http://www.hq.nasa.gov/ofice/aero/programs fap.htm.

${ }^{22}$ Mukhopadhyay, V., Sobieszczanski-Sobieski, J., Kosaka, I., Quinn, G., and Vanderplaats, G., "Analysis, Design and Optimization of Non-cylindrical Fuselage for Blended-Wing-Body Vehicle," Journal of Aircraft, Vol. 41, No. 4, JulyAugust, 2004, pp. 925-930.

${ }^{23}$ Mukhopadhyay, V, "Blended-wing-body fuselage concept structural design for weight reduction,” AIAA Paper 2005-2349.

${ }^{24}$ Bruhn, E. F., "Analysis and Design of Flight Vehicle Structures," Tri-State Offset Co., Cincinnati, Ohio, 1965, Chapter A16, pp. A16.1-A16.9 and Chapter C11, pp. C11.29-C12.51.

${ }^{25}$ Niu, M. C. Y., "Airframe Structural Design," Conmilit Press Ltd., Hong Kong, 1993, Chapter 11, pp. $376-428$.

${ }^{26}$ Mukhopadhyay, V., "Structural Configuration Analysis of Crew Exploration Vehicle Concepts," AIAA Paper $2006-2082$.

${ }^{27}$ Mukhopadhyay, V., "Solid Modeling of Crew Exploration Vehicle Structure Concepts for Mass Optimization," AIAA Paper 2006-7126. 